\title{
Espondilodiscite por brucelose: relato de caso
}

\author{
Brucellosis spondylodiscitis: case report
}

\author{
Caroline Castro Figueira de Mello ${ }^{1}$, Daltono Umberto de Souza ${ }^{1}$, \\ Francisco Antônio Capita Glória ${ }^{1}$, Leonardo Oliveira Moura ${ }^{2}$ \\ e George Castro Figueira de Mello $^{3}$
}

\begin{abstract}
RESUMO
Relata-se um caso de espondilodiscite por Brucella em um paciente do sexo masculino, 56 anos, fazendeiro, com manifestações sistêmicas da doença. O diagnóstico foi realizado por sorologia com título de 1/160, hemocultura positiva, o VHS foi elevado, bem como alterações radiológicas mostraram espondilodiscite ao nivel de T8/T9 compatíveis com a patologia. O paciente foi tratado com estreptomicina 1 gIM/dia por 15 dias, doxaciclina e rifampicina por seis semanas, com melhora clínica do quadro. O envolvimento vertebral na brucelose é uma complicação de ocorrência variável na literatura, mas considerado pouco freqüiente, de difícil diagnóstico principalmente em regiões com alta prevalência de tuberculose, visto que esta pode mimetizar o quadro de brucelose. Chama-se atenção a um caso raro de espondilodiscite por brucelose, dada a necessidade de diagnóstico precoce e tratamento a fim de se evitar possíveis seqüelas.
\end{abstract}

Palavras-chaves: Brucelose. Espondilodiscite. Envolvimento vertebral por Brucella sp. Tratamento.

\section{ABSTRACT}

A case of spondylodiscitis due to Brucella with systematic manifestation of the disease, in a 56-year-old male patient who was a farmer, is reported. The diagnosis was made from serological tests, with a titer of 1/160. The blood culture was positive and the blood sedimentation rate was high. Radiological abnormalities showed spondylodiscitis at the T8/T9 level that were compatible with this disease. The patient was treated with streptomycin at $1 \mathrm{~g}$ IM/day for 15 days, and doxycycline plus rifampicin for six weeks, with a clinical improvement in the condition. Vertebral involvement in brucellosis is a complication of variable occurrence in the literature. However, it is considered to be infrequent and difficult to diagnose, particularly in regions with high prevalence of tuberculosis, given that this may mimic conditions of brucellosis. Attention is drawn to this rare case of spondylodiscitis due to brucellosis, given the need for early diagnosis and treatment in order to avoid possible sequelae.

Key words: Brucellosis. Spondylodiscitis. Vertebral involvement by Brucella sp. Treatment.

Brucelose é uma patologia também conhecida como: febre do Mediterrâneo, febre de Malta e febre ondulante, considerada a maior zoonose do mundo 7 . É causada por um coco-bacilo Gram-negativo do gênero Brucella ${ }^{8}$. Os reservatórios animais tais como: bovinos; suínos; caprinos; caninos constituem a fonte de infecçã $0^{411}$. A brucelose é um importante problema de saúde pública em determinadas áreas do mundo, como: Mediterrâneo e Leste Médio. Naquelas regiões a espécie bacteriana mais prevalente é a Brucella melitensis, proveniente dos caprinos,

já na América latina e no Brasil a espécie mais envolvida é Brucella abortus cujo reservatório são os bovinos ${ }^{1316}$. No Brasil, é uma doença ocupacional ${ }^{4}$. A transmissão dá-se através do consumo de produtos infectados, tais como: leite não pasteurizado e seus derivados; contato direto com animais infectados ou inalação de partículas de aerossóis contendo fragmento bacteriano ${ }^{571118}$. Clinicamente, a doença caracteriza-se, geralmente, como uma febre de origem indeterminada, envolvendo muitos órgãos e tecidos com sintomas constitucionais como: perda ponderal, astenia, lombalgia, artrite, entre outros ${ }^{616}$. 0 envolvimento vertebral é o mais difícil de se diagnosticar e tratar devido ao longo período de latência da infecção. A rotina clínica e laboratorial pode não ser suficiente para diagnosticar a patologia, uma vez que a lombalgia pode fazer parte do curso natural da doença ${ }^{61213}$. 0 diagnóstico de brucelose vertebral é feito baseado em características clínicas, laboratoriais e achados radiológicos ${ }^{1320}$.

1. Setor Clínica Médica, Hospital Regional de Taguatinga, Taguatinga, DF. 2. Setor Radiologia e Diagnóstico por Imagem, Hospital Regional de Taguatinga, Taguatinga, DF. 3. Curso de Pós-Graduação, Faculdade de Medicina, Universidade de São Paulo, São Paulo, SP.

Endereço para correspondência: Dr ${ }^{\mathrm{a}}$ Caroline Castro Figueira de Mello. Área Especial/Setor Clínica Médica/HRT. 72115-115 Taguatinga, DF.

e-mail: carolinecfm@hotmail.com

Recebido em: 03/07/06

Aceito em: 03/07/06 


\section{RELATO DE CASO}

Paciente de 56 anos, sexo masculino, fazendeiro, casado, natural de Redenção/PA, cursando há cerca de dois meses com febre baixa, principalmente vespertina, não aferida, perda ponderal de $8 \mathrm{~kg}$ nesse período associada lombalgias há uma semana. Ficou internado por dois dias no Hospital municipal de Redenção, onde fez uso de medicações que desconhecia, recebendo alta sem diagnóstico. Negava alterações urinárias, fecais, náuseas ou vômitos. Referia consumo de leite não pasteurizado e contato direto com secreções bovinas, tendo hábito de auxiliar em partos bovinos. 0 exame físico foi normal. Solicitaram-se exames para esclarecimento do quadro febril: hemograma e bioquímica, velocidade de hemossedimentação (VHS), purified protein derivative (PPD), reticulócitos, ecocardiograma, sorologias para HIV, mononucleose, brucelose, fator antinuclear (FAN), fator reumatóide (FR), toxoplasmose, citomegalovírus (CMV), teste para malária e radiografia tóraco-lombar. Prescreveram-se apenas sintomáticos. Os exames solicitados revelaram: VHS= $54 \mathrm{~mm} / \mathrm{hr}$; PPD negativo; teste para malária negativo; Hemograma com leucócitos de 7.200 com 75,5\% neutrófilos e 19,7\% linfócitos, demais exames não revelaram anormalidades. 0 teste de rosa bengala para brucelose foi positivo. Como não se dispunha da titulação em nossa instituição, solicitou-se que esta fosse realizada em outro laboratório, cujo resultado foi negativo. 0 paciente persistia com quadro lombálgico importante, tendo apresentado episódios febris esporádicos com cerca de $38^{\circ} \mathrm{C}$. Após um mês da internação, o paciente apresentou parestesias de membros inferiores (MMIIs), solicitaram-se tomografia computadorizada (TC) e ressonância nuclear magnética (RNM) da coluna tóraco-lombar que evidenciaram as seguintes alterações (Figuras 1, 2 e 3).

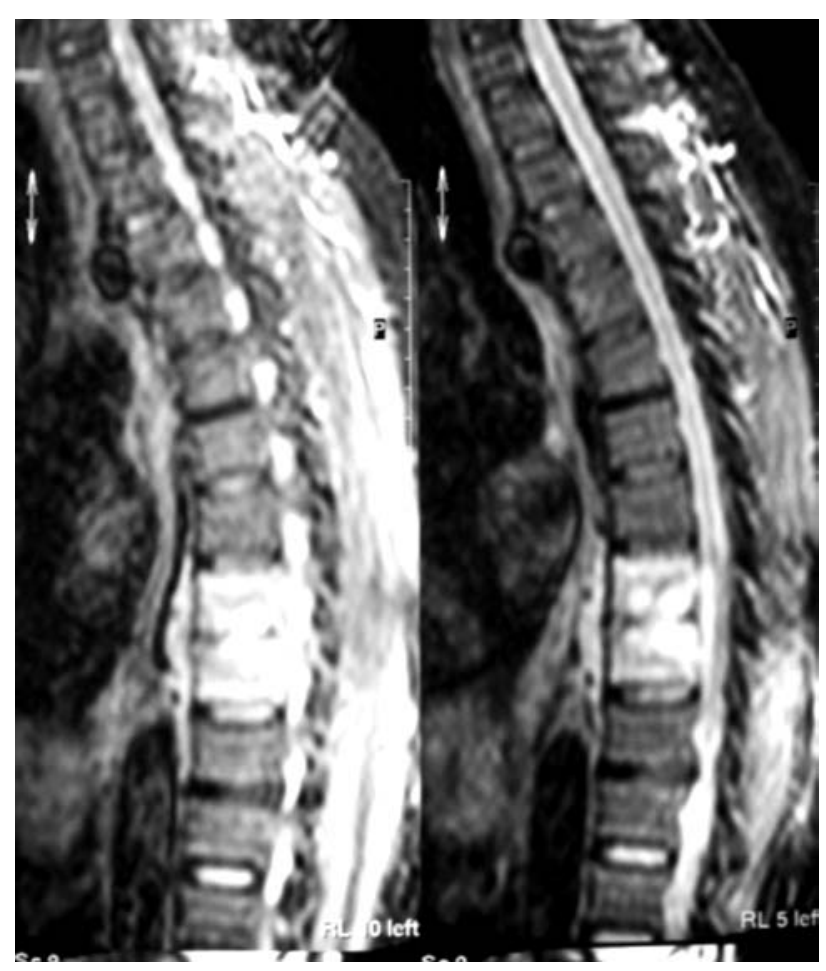

Figura 1 - Cortes sagitais de ressonância magnética (T2) demonstrando bipersinal dos corpos vertebrais de T8 e T9 e das partes moles adjacentes, redução do espaço intervertebral sugerindo espondilodiscite ao núvel de T8/T9.

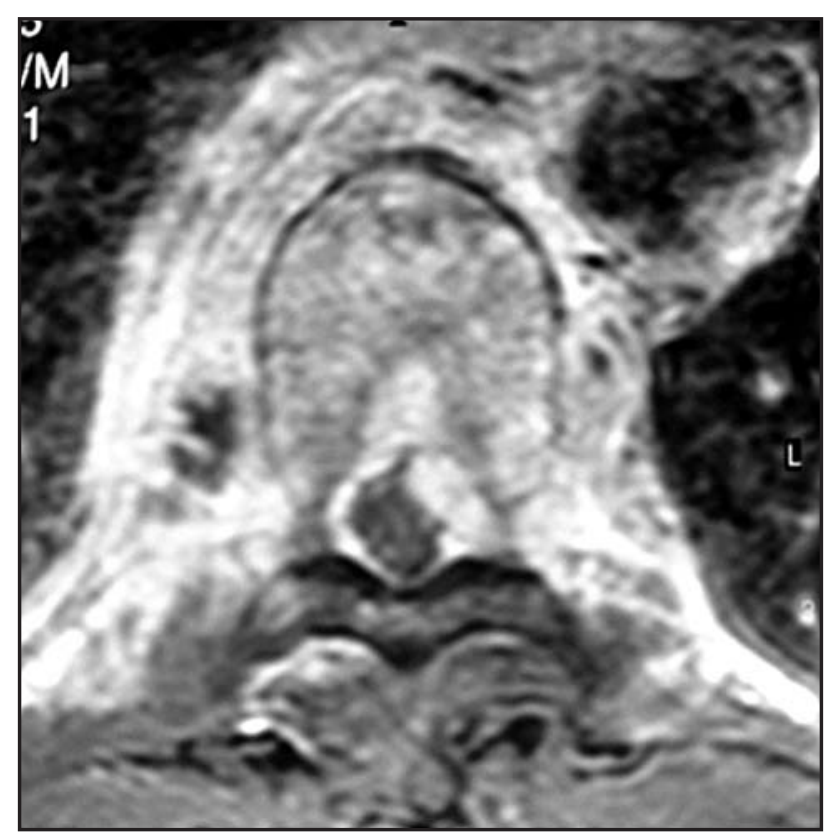

Figura 2 - Corte axial de ressonância magnética (T1 pós-contraste) exibindo aumento de partes moles perivertebrais com realce pelo meio de contraste, além de extensão para o canal vertebral comprimindo a medula.

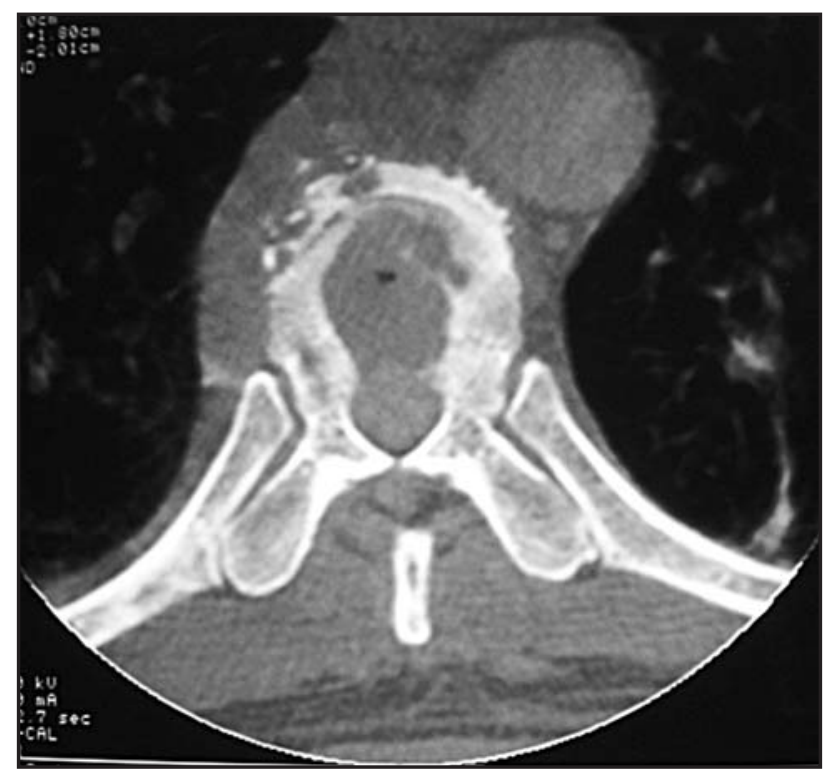

Figura 3 - Corte axial de tomografia computadorizada ao nível de T8 demonstrando áreas líticas do corpo vertebral e aumento das partes moles adjacentes.

Neste ínterim, o paciente iniciou uso de colete vertebral, foi sugerida possibilidade de tuberculose vertebral, optou-se por iniciar esquema RIP(rifampicina + isoniazida + pirazinamida) enquanto nova sorologia para brucelose e hemoculturas eram aguardadas. Nova radiografia simples da coluna dorsal mostrou redução assimétrica do espaço discal de T8/T9 com fuso paravertebral (Figura 4). 0 paciente evoluiu sem melhora clínica após uma semana do esquema tuberculostático, quando o segundo exame de titulação para brucelose revelou-se positivo com título 1/160 e a cultura para brucelose foi positiva. Iniciou-se tratamento para brucelose com estreptomicina 1g/dia IM por 15 dias, associado a doxiciclina $200 \mathrm{mg} /$ dia e rifampicina $600 \mathrm{mg} / \mathrm{dia}$ 
por 45 dias. Com o início da terapêutica o paciente apresentou melhora significativa do quadro e resolução do quadro álgico após um mês de tratamento. No momento, mantêm retornos periódicos dada a possibilidade de recaídas.

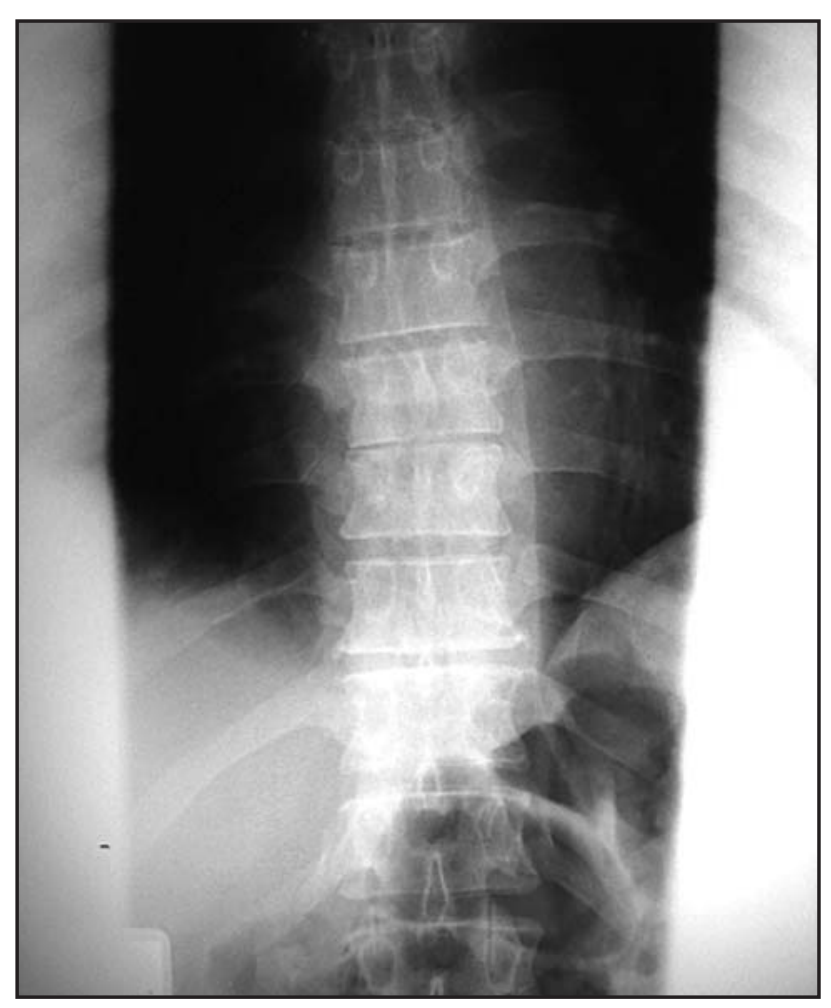

Figura 4 - Radiografia da coluna torácica na incidência ântero-posterior demonstrando redução assimétrica do espaço discal de T8/T9 com fuso paravertebral.

\section{DISCUSSÃO}

A distribuição mundial da brucelose é de cerca de $500 \mathrm{mil}$ casos por ano, com letalidade de 1-6\% dos casos não tratados ${ }^{4}$. A incidência nos EUA é de cerca de 0,1 casos por 100.000 habitantes, no Leste Médio esta estimativa é de 86 casos para 100.000 habitantes $^{13}$. No Brasil, não há dados estatísticos exatos, mas acredita-se que a doença seja subdiagnosticada com cerca de 25 casos não conhecidos para cada um conhecido ${ }^{6}$.

0 envolvimento osteoarticular é o mais comum na brucelose e inclui a forma de artrite periférica, sacroileíte e espondilodiscite nessa ordem de prevalência ${ }^{20}$. Em estudos realizados por Colmenero e cols ${ }^{2}$ e Solera e cols 1999 (apud: Zormpala e cols, 2000), com respectivamente, 583 e 285 pacientes com brucelose, observou-se acometimento na forma de espondilite em 9,7\% e $12.3 \%$ dos casos.

Kulowski and Vince, em 1932 (apud: Tekkeök e cols), foram os primeiros a descreverem a espondilodiscite como complicação $0^{13}$. 0 envolvimento osteoarticular na brucelose é um grande desafio diagnóstico, uma vez que o período de latência da infecção é variado e longo, a rotina clínico-laboratorial nem sempre é suficiente para definir este acometimento, visto que lombalgias podem fazer parte do curso natural da doença ${ }^{6}{ }^{12}$.
Além disso, o diagnóstico diferencial torna-se difícil, pois o envolvimento vertebral por brucelose pode mimetizar uma série de patologias como: espondilodiscite tuberculosa; osteomielite piogênica; lesões metastáticas; plasmocitoma; actinomicoses e hérnia de disco ${ }^{13}$. No Brasil, o principal diagnóstico diferencial é a tuberculose vertebral, devido à alta prevalência desta entidade patológica em nosso país ${ }^{6}$. Na tentativa de permitir um diagnóstico precoce do envolvimento vertebral por brucelose, muitos estudos têm sido reportados para avaliar diferenças entre paciente com e sem espondilite. Namiduru e cols ${ }^{12}$ e Budur e cols ${ }^{1}$ mostraram que, pacientes com espondilite por brucelose apresentavam idade mais elevada, maior duração da sintomatologia e VHS elevado em relação aos pacientes com brucelose sistêmica, conforme observado em nosso paciente. No caso apresentado, o paciente tinha 56 anos, VHS elevado e o tempo de aparecimento dos sintomas foi de 2 meses. A primeira sorologia solicitada mostrouse positiva e a primeira titulação solicitada em outro laboratório, apresentou-se negativa. Tal fato retardou o diagnóstico da doença, fazendo-nos pensar em tuberculose como principal hipótese diagnóstica, uma vez que esta é endêmica em nosso país, optandose pelo início do esquema RIP enquanto novas sorologias eram aguardadas. Após uma semana o paciente apresentou sintomas neurológicos, requerendo uso de colete. Com a chegada de nova sorologia revelando titulação 1/160, cultura isolando Brucella sp, iniciou-se tratamento específico com doxiciclina 100mg 2x/dia, rifampicina 300mg 2x/dia por 45 dias e estreptomicina $1 \mathrm{~g}$ IM nos primeiros 15 dias. Após uma semana desta terapêutica, o paciente apresentou melhora significativa do quadro álgico. Com o término do tratamento o paciente não apresentou mais queixas clínicas e no momento, faz acompanhamento regular no ambulatório.

A radiografia da coluna dorsal tem baixa sensibilidade no diagnóstico precoce do envolvimento vertebral, pois as lesões observadas ao Rx são vistas após longo tempo da doença. No nosso paciente, as alterações radiológicas ao $\mathrm{Rx}$ apareceram aproximadamente três meses após o início dos sintomas, pois a radiografia da admissão do paciente mostrou-se normal e quando realizado um mês depois da internação revelou redução do espaço discal ao nível de T8-T9. Contudo, a tomografia e a RNM mostramse sensíveis em detectar estas alterações precocemente ${ }^{9}$. 0 aspecto radiológico na RNM mostra o corpo vertebral parcialmente homogêneo com hiposinal em T1 e hipertensidade em T2, nos casos avançados com redução do espaço intervetebral ocorre diminuição da intensidade para fibrose em T2. No envolvimento paravertebral, geralmente observa-se, edema de partes moles sem a presença de abscessos e com envolvimento da faceta vertebral. O segmento vertebral mais envolvido na espondilodiscite por brucelose é o lombar, mais freqüentemente nas vértebras L4-L5, seguido do torácico (como no presente caso) e finalmente o cervical $^{9}{ }^{1020}$. Em nosso paciente, os achados radiológicos foram similares, sendo observado mudança do sinal no corpo vertebral e pedículos de T8-T9 com áreas líticas, destruição vertebral, compressão do cordão espinhal justificando as parestesias referidas. As manifestações neurológicas são vistas em $2 \%$ dos casos e são mais freqüentemente associadas ao envolvimento cervical $^{8}$. 
Ao relatar este caso, objetiva-se chamar atenção para diagnóstico precoce de brucelose e principalmente, do seu envolvimento vertebral. Uma vez que, os casos diagnosticados tardiamente podem levar a seqüelas irreparáveis e complicações neurológicas ${ }^{14}$. Devemos atentar para 0 diagnóstico diferencial com tuberculose principalmente em pacientes com epidemiologia positiva e proveniente de áreas endêmicas para esta patologia, como o Brasil. A RNM e TC mostram-se extremamente sensíveis à detecção do envolvimento vertebral. A opção terapêutica mais referida na literatura é o esquema tríplice estreptomicina, doxiciclina e rifampicina por pelo menos 45 dias, preconizado também pela OMS, no entanto, muitas opções terapêuticas vêm sendo reportadas ${ }^{141520}$. Desse modo o diagnóstico precoce é importante, a fim de permitir o tratamento adequado e eficiente. Considerando os impactos sócio-econômicos dessa patologia, torna-se necessário orientar a população quanto à prevenção da doença, bem como medidas mais eficazes para sua erradicação.

\section{REFERÊNCIAS}

1. Bodur H, Ayse E, Alin C, Esragül A. Brucellar spondylitis. Rheumatology International 24: 221-226, 2004.

2. Colmenero JD, Jiménez-Mejías ME, Sànchez-Lora FJ, Reguera JM, Palomino-Nicás J, Martos F, García de las Heras J, Pachón J. Pyogenic, tuberculous, and brucellar vertebral osteomyelitis: a descriptive and comparative study of 219 cases. Annals of Rheumatic Diseases 56: 709-771, 1997.

3. Cordero M, Sánchez I. Brucellar and Tuberculous spondylitis. The journal of bone and joint surgery 73-B: 100-103, 1991.

4. Couto DFM, Pedroso ERP. Doenças Infecciosas e Parasitárias relacionadas ao trabalho In: Mendes R (ed) Patologia do trabalho. $2^{\text {a }}$ edição, Editora Atheneu, São Paulo, volume 1, capitulo 19, p. 892-893, 2003.

5. Cutler SJ, Whatmore AM, Commander NJ. Brucellosis - new aspects of an old disease. Journal of Applied Microbiology 98: 1270-1281, 2005.

6. Ferreira CR, Ferreira CR, Tatagiba TA, Souto Filho JTD. Espondilodiscite brucelósica: relato de caso. Revista da Sociedade Brasileira de Medicina Tropical 35:255-258, 2002.
7. Godfroid J, Cloeckaert A, Liautard JP, Kohler S, Fretin D, Walravens K, Garin-Basturi B, Letesson JJ. From the discovery of the Malta fever's agent to the discovery of marine mammal reservoir, brucellosis has continuosly been a re-emerging zoonosis. Veterinary Research 36: 313-326, 2005.

8. Lorido JC, Gómez CJ, Requena RJ, Dacal BJC, Tomé AV, Dacal BP. Brucellar spondylitis and meningoencephalitis: a case report. The Netherlands Journal of Medicine 59: 158-160, 2001.

9. Maiuri F, Giorgio I, Biagio G, Manto A, Briganti F. Spondylodiscitis: Clinical and Magnetic Resonance Diagnosis. Spine 22: 1741-1746, 1997.

10. Mantle JA. England B .Brucellar spondylitis. The Journal of Bone and Joint Surgery 37B: 1955.

11. Ministério da Saúde. Doenças relacionadas ao trabalho: Manual de procedimento. Brasília, p 66-68, 2001.

12. Namiduru M, Ilkay K, Savas G, Nurhauat B, Akif S. Brucellosis of the spine: evaluation of the clinical, laboratory, and radiological findings of 14 patients. Rheumatology International 24: 125-129, 2004.

13. Ozakoy D, Yücesoy K, Yücesoy M, Kovanhkaya I, Yüce A, Naderi S. Brucellar spondylitis: MRI findings. European Spine Journal 10: 529-533, 2001.

14. Pappas; G, Seitaridis S, Akritidis N, Tsianos E. Tratament of brucella spondylitis: lessons from an impossible meta-analysis and initial report of efficacy of a fluorquinolone-containing regimen. International Society of Chemotherapy 24: 502-507, 2004.

15. Pappas G, Solera J, Akritidis N, Tsianos E. New approaches to the antibiotic Treatment of brucellois. International Journal of Antimicrobial Agents $26: 101-105,2005$.

16. Pappas G, Akritidis N, Bosilkovski M, Tsianos E. Brucellosis. The New England Journal of Medicine 352: 22, 2005.

17. Pilar JBM, Dudal S, Dornand J, Gross A. Cellular bioterrorism: how brucella corrupts macrophage physiology to promote invasion and proliferation. Clinical Immunology 114: 227-238, 2005.

18. Salata R. Brucelose. In: Gooldman L, BenettJC (eds) Tratado de Medicina Interna. Cecil. Editora Guanabara, Rio de Janeiro, p. 1915-1918, 2003.

19. Turgut M, Sendur OF, Gürel M. Brucellar spondylodiscitis in the lumbar region. Neurologia Medico-Chirurgica (Tokyo) 43:210-212, 2003.

20. Zompala A, Skopelitis E, Thanos L, Artinopoulos C, Kordossis T, Sipsas NV. An unusual case of brucellar spondylitis involving both the cervical and lumbar spine. Journal of Clinical Imaging 24: 273-275, 2000. 